\title{
PENGEMBANGAN"PASIRAMAN PURA DALEM PINGIT DAN PURA KUSTI" SEBAGAI DAYA TARIK WISATA SPIRITUAL DI DESA BATUAN GIANYAR
}

\author{
I Made Darma Oka ${ }^{1}$, Made Sudiarta ${ }^{2}$, I Gede Astawa ${ }^{3}$, I Wayan Sukita ${ }^{4}$ \\ Politeknik Negeri Bali ${ }^{1,2}$ \\ madedarmaoka@pnb.ac.id ${ }^{1}$; mdsudiarta@pnb.ac.id ${ }^{2}$ \\ Akademi Pariwisata Denpasar ${ }^{3,4}$ \\ gedeastawa@akpar-denpasar.ac.id ${ }^{3 ;}$ wayansukita2014@gmail.com ${ }^{4}$
}

Received: February 2, 2021 | Accepted: March 1, 2021 | Published: May 1, 2021

Permalink/DOI: https://doi.org/10.53356/diparojs.v1i2.31

\begin{abstract}
ABSTRAK
Artikel ini bertujuan untuk menganalisis kelayakan dari "Pasiraman Pura Dalem Pingit dan Pura Kusti" untuk dikembangkan menjadi daya tarik wisata berdasarkan aspek komponen destinasi pariwisata, seperti attraction, accessibilites, amenities, dan ancillary service. Pengumpulan data dilakukan dengan metode observasi, wawancara, dan studi pustaka dengan analisis deskriptif kualitatif. Hasil penelitian menunjukkan bahwa "Pasiraman Pura Dalem Pingit dan Pura Kusti" layak untuk dikembangkan menjadi daya tarik wisata guna menjadi alternatif bagi wisatawan dalam memilih destinasi yang dikunjungi. Kelayakan ini dilihat dari fasilitas komponen pariwisata yang dimiliki, seperti: Pura tempat sembahyang, tempat suci untuk melukat, tempat parkir, restoran, ruang ganti pakaian, toilet, tempat penjualan sarana sembayang, dan puskesmas di wilayah desa. Wisatawan yang berkunjung ke destinasi wisata ini tidak hanya sekedar untuk melihat keindahan panorama alam maupun keunikan budaya lokal tetapi mereka cenderung untuk terlibat langsung dalam kegiatan pariwisata spiritual. Untuk itu disarankan agar daya tarik wisata ini dikelola secara profesional dan berkelanjutan sehingga dapat bersaing secara kompetitif dengan daya tarik wisata lain.
\end{abstract}

Kata Kunci: Pengembangan, daya tarik wisata, pariwisata spiritual

\begin{abstract}
The aims of this paper to analyze the feasibility of "Pasiraman Pura Dalem Pingit and Pura Kusti" to develop into tourist attractions-based tourism destination components aspect, such as attractions, accessibility, amenities, and ancillary service. Observation data, interviews, and literature study method with qualitative descriptive analysis used in this paper. It is shown that "Pasiraman Pura Dalem Pingit and Pura Kusti" feasible to develop into tourist attraction to be an alternatives when choose the tourist attraction. This feasibility is seen by the tourism facilities component are owned, such as: Temples as place of worship, places to do "melukat", parking lots, restaurants, fitting rooms, toilets, shelters, and "puskesmas" in village area. Tourists that visiting tourist attraction not only see the beauty of the natural panorama or the uniqueness of the local culture but directly involved spiritual tourism activities. For this reason, this tourist attraction suggested to manage professionally and sustainable so it can compete with the others.
\end{abstract}

Keywords: Development, tourist attraction, spiritual tourism 


\section{PENDAHULUAN}

Berwisata merupakan suatu gaya hidup bahkan lebih penting dari hanya sekedar upaya pemenuhan karir dan finansial. Kegiatan berwisata berkeliling dunia, menemukan tempat baru, suasana dan pengalaman yang tidak terlupakan, ditemani orang-orang tercinta merupakan bagian dari mimpi yang ingin diwujudkan oleh setiap orang suatu hari nanti. Salah satu mimpi wisatawan sebelum mereka terlambat adalah mengunjungi pariwisata Bali.

Bali memang identik dengan pariwisata. Bali dan pariwisata adalah dua hal yang saling melengkapi satu dengan yang lain. Bali merupakan ikon pariwisata Indonesia. Ketika berbicara kepariwisataan Indonesia, Bali selalu ditempatkan pada posisi tertinggi, baik sebagai destinasi wisata unggulan maupun sebagai rujukan model pengembangan pariwisata di daerah lainnya.

Kunjungan wisatawan asing ke Bali meningkat dalam lima tahun terakhir, dengan pertumbuhan $>28 \%$ (Disparda Bali, 2020). Kondisi ini memotivasi masyarakat Bali untuk terus menggali dan mengembangkan segenap potensi desa yang dimiliki untuk dapat dikembangkan dalam mendukung aktivitas pariwisata.

Dipahami bahwa sektor pariwisata di Bali merupakan penggerak perekonomian masyarakat diharapkan dapat berkelanjutan melalui pengembangan pariwisata berbasis masyarakat. Dalam usaha merealisasikan pembangunan pariwisata berkelanjutan yang berbasis masyarakat, diperlukan upaya diversifikasi daya tarik wisata yang berorientasi pada peningkatan kesejahteraan masyarakat, pelestarian seni budaya, dan pembangunan kepariwisataan yang ramah lingkungan. Pengembangan wisata seperti ini kini dikenal juga dengan istilah 'pariwisata pro-rakyat' (Putra dan Pitana 2010). Salah satu pilihan tepat adalah membentuk kawasan wisata pedesaan yang dapat dijadikan daya tarik wisata yang biasa dikenal dengan desa wisata.

Pengembangan desa di Kabupaten Gianyar cenderung lebih menonjolkan suasana pedesaan dan keaslian sosial budaya masyarakat lokal (Mahadewi dan Sudana (2017). Selama ini pengembangan pariwisata sifatnya monoton pada daya tarik wisata yang sudah terkenal, belum adanya inovasi untuk mengkolaborasi antara potensi alam, budaya dan kreatifitas masyarakat setempat, sehingga memunculkan adanya kesan kemiripan atau kesamaan antara daya tarik wisata yang satu dengan yang lainnya dan sudah mulai adanya kecenderungan daya tarik wisata mulai ditinggalkan wisatawan seperti desa Petulu dan desa wisata Batubulan. Salah satu terobosan inovasi yang perlu dilakukan adalah melalui pengembangan desa wisata.

Salah satu desa yang mengembangkan potensi pariwisata sebagai daya tarik wisata adalah desa Batuan, Gianyar, Bali. Potensi pariwisata yang dikembangkan di desa ini merupakan daya tarik wisata (DTW) unik bagi wisatawan untuk menyegarkan pikiran. DTW yang dikembangkan yaitu pariwisata spiritual bernama Pasiraman Pura Dalem Pingit dan Pura Kusti. Di DTW ini wisatawan bisa membersihkan diri melalui penyucian diri (melukat). Melalui penyucian diri (melukat) dipercaya mampu menghilangkan segala pikiran kotor, jenuh, dan pengaruh black magic sehingga mereka dalam menjalani kehidupan bisa dengan tenang, nyaman, damai, dan bahagia.

Dalam pengembangan daya tarik wisata "Pasiraman Pura Dalem Pingit dan Pura Kusti"ini perlu dilakukan evaluasi berdasarkan kriteria atau komponen yang harus dimiliki dalam pengembangan daya tarik wisata. Adapun komponen yang dimaksud terdiri atas: attraction, access, amenities, and ancillary services (4A). 
Terkait dengan hal tersebut paper ini mengkaji tentang kelayakan "Pasiraman Pura Dalem Pingit dan Pura Kusti” untuk dikembangkan menjadi daya tarik wisata spiritual ditinjau dari berbagai komponen pendukungnya. Diharapkan pengembangan pariwisata spiriual ini dapat memberikan kontribusi bagi kehidupan masyarakat lokal baik dari segi ekonomi, sosial, maupun budaya.

\section{KAJIAN LITERATUR}

Pariwisata telah menjadi aktivitas sosial ekonomi dominan bagi kehidupan masyarakat Bali. Cole (2012) menyebut bahwa kehidupan masyarakat Bali dominan (80\%) memiliki ketergantungan dengan aktivitas pariwisata. Untuk itu keberlanjutan aktivitas pariwisata di Bali harus dipertahankan agar mampu meningkatkan kesejahteraan bagi kehidupan masyarakat. Sutrisna (2011); Oka \& Pugra (2017); Oka, dkk (2021) menyebutkan bahwa sektor pariwisata telah mampu menciptakan kesempatan kerja dan pemberdayaan bagi masyarakat melalui terbukanya berbagai jenis usaha yang terkait dengan kepariwisataan dapat dimanfaatkan oleh para tenagakerja. Munculnya kesempatan kerja tersebut dapat menyebabkan tenagakerja Bali bergantung kepada aktivitas pariwisata.

Terkait dengan hal itu citra atau image positif pariwisata Bali harus tetap dipertahankan bahkan terus ditingkatkan karena kunjungan para wisatawan ke Bali tentu secara langsung ataupun tidak langsung akan mempromosikan keberadaan destinasi Bali melalui berbagai media sosial kepada teman dan kolega bahwa mereka lagi berada di daerah tujuan wisata baru yang berbeda dengan daerah wisata lainnya. Informasi tersebut merambah cepat akan memberitakan atau mempublikasikan aktivitas liburan mereka di Bali membuat Bali semakin dibicarakan oleh wisatawan di mancanegara.

Image destinasi adalah image yang mempunyai arti tinggi terhadap dampak pada perilaku perjalanan wisatawan dalam menentukan proses pemilihan tujuan destinasi yang akan dikunjungi. Hall dan O'Sullivan (Zahra, 2012) menyebutkan terdapat tiga unsur-unsur yang menyebabkan suatu destinasi survival dalam permintaan jangka panjang, yaitu: (1) informasi lisan dari kembalinya wisatawan ke negaranya, (2) image yang dibuat oleh media dan (3) kemauan dan kebijakan dari pemerintah setempat. Suatu image dapat dilihat sebagai bentuk gambaran mental oleh satu set atribut yang menggambarkan motivasinya dalam berbagai dimensi sehingga dalam proses pemilihan destinasi menjadi berpengaruh.

Selanjutnya Beerli dan Martin (2004) menyebutkan bahwa suatu image destinasi dapat diciptakan dari perasaan perorangan, kelompok atau pengetahuan, pengaruh eksternal seperti pengaruh dari para teman dan keluarga, iklan dan pengalaman masa lampau mereka. Budiasih (2017) menyebut kemajuan perkembangan teknologi informasi (media sosial), seperti internet dan turunannya, seperti: facebook, twitter, email, blog, online, dan yang lainnya memiliki andil besar sebagai trigger atau pull factor, bagi wisatawan untuk melakukan perjalanan wisata ke destinasi pariwisata. Indikasi ini menciptakan suatu image dalam pikiran konsumen tergantung pada tingkat keakraban yang diperoleh dari semua sumber sosial dan budaya serta yang paling penting kemampuan dari Destination Management Organization (DMO), untuk memahami atau memenuhi harapan customer atas produk pariwisata yang ditawarkan.

Sejalan dengan adanya perubahan trend berwisata yaitu dari mass tourism ke 
small group tourism, gerak perkembangan pariwisata telah merambah dalam konsep pengembangan pariwisata berkelanjutan, seperti: ekowisata, desa wisata, agrowisata, pariwisata spiritual, hingga pariwisata berbasis masyarakat mulai diterapkan untuk memaksimalkan pengembangan destinasi (Sastrayuda, 2010: 2). Bali memiliki peluang besar untuk mengembangkan wisata jenis spiritual ini karena relevan dengan tradisi dan budaya masyarakat. Namun di tengah peluang tersebut, masih ada beberapa tantangan yang dihadapi diantaranya sumber daya yang masih minim, sarana prasarana, pola pengembangan, serta regulasinya perlu digarap dengan lebih serius (Utama dan Wiguna, 2020).

Pemda Bali telah menetapkan bahwa pariwisata yang dikembangkan di Bali adalah pariwisata budaya. Pengembangan pariwisata yang berlandaskan pada budaya Bali ini dimana nafas pengembangan pariwisatanya sejalan dengan tradisi budaya masyarakat sehingga mampu menumbuhkan kesadaran masyarakat dalam melestarikan budaya. Salah satu pariwisata budaya yang sedang marak dikembangkan guna menarik minat wisatawan berkunjung ke Bali adalah pariwisata spiritual.

Pengembangan pariwisata spiritual penting dipertimbangkan sebagai bentuk pengejawantahan pariwisata alternatif. Wisata spiritual merupakan salah satu daya tarik wisata yang potensial untuk dikembangkan di Bali. Potensi wisata spiritual yang ada merupakan modal wisata budaya sebagai daya tarik wisata minat khusus (Lagatama \& Putra, 2020). Potensi wisata spiritual merupakan modal dalam mengembangkan sektor pariwisata, termasuk yang kini sedang berkembang di Pasiraman Pura Dalem Pingit dan Pura Kusti di Batuan Gianyar. Dalam pengembangan wisata spiritual memerlukan terobosan untuk menarik kedatangan lebih wisatawan yang berkunjung, seperti aktivitas penyucian diri (melukat). Aktivitas melukat ini hendaknya dikemas sedemikian rupa dan dijelaskan kepada wisatawan secara lugas dan sistematis sehingga mereka memahami makna dari melukat secara komprehensif.

Pasiraman Pura Dalem Pingit dan Pura Kusti dibangun menjadi pura sebagai sumber air yang kini disucikan, dahulu digunakan oleh masyarakat lokal sebagai tempat mandi. Sumber air ini diketahui merupakan sebuah sumber air suci pada tanggal 19 November 2007 ketika salah seorang wisatawan yang diajak oleh seorang masyarakat untuk melihat daya tarik yang ada di Desa Sebatu. Ketika wisatawan tersebut mandi di air suci ini, kemudian air suci tersebut menjadi berubah warna. Perubahan warna air ini dicari tahu penyebabnya oleh pemangku setempat menggunakan prosesi Hindu dan diketahui bahwa sumber air ini adalah air suci. Akhirnya pada tanggal 24 November 2007 di tempat itu mulai dilakukan pembangunan pura karena tanggal itu merupakan hari baik. Lahan milik masyarakat di sekitar pura direlakan untuk digunakan sebagai tangga menuju ke pura.

Kunjungan wisatawan asing ke pura ini lambat laun semakin meningkat dengan rata-rata kunjungan mencapai $>1.180$ orang/bulan (Mahardika, 2018). Sedangkan wisatawan domestik yang berkunjung ke pura ini karena mereka ingin membuktikan apakah benar-benar berkhasiat seperti yang mereka dengar dalam cerita di masyarakat. Ada masyarakat Desa Sebatu ikut membuktikan dengan mengajak rekannya yang sakit untuk mencoba mengobati penyakitnya dan ternyata sembuh setelah melukat di sana. Semenjak saat itu tidak hanya umat Hindu yang percaya dengan khasiat yang diberikan air suci ini, bahkan wisatawan asing juga diajak 
oleh masyarakat Desa Sebatu untuk berkunjung dengan tujuan memperkenalkan kepada wisatawan asing, walaupun kebanyakan wisatawan asing hanya melihat dan berfoto, namun ada beberapa diantaranya yang tertarik untuk melukat.

\section{METODE PENELITIAN}

Artikel ini menggunakan data kualitatif. Pengumpulan data melalui metode observasi, wawancara mendalam, dan studi pustaka. Data informasi terkait kelayakan "Pasiraman Pura Dalem Pingit dan Pura Kusti" diperoleh dari tokoh masyarakat/pengelola DTW yang memahami tentang hal tersebut. Jumlah informan tidak ditentukan secara pasti. Penentuan informan dilakukan secara snowball sampling. Informan pertama diambil dari tokoh masyarakat (Kepala Desa), selanjutnya dilakukan pencarian informan lain atas petunjuk dari informan pertama, demikian seterusnya. Ketika jawaban sudah jenuh pengumpulan data dihentikan. Data dianalisis secara deskriptif kualitatif, melalui pengolahan dan penafsiran data yang merupakan rangkaian kegiatan penelahaan, pengelompokan, sistematisasi, penafsiran dan reifikasi data agar sebuah fenomena memiliki nilai sosial, akademis dan nilai ilmiah (Bungin, 2011).

\section{PEMBAHASAN}

Mengkaji kelayakan dari suatu tempat untuk dapat dijadikan sebagai daya tarik wisata setidaknya harus memiliki komponen (UNESCO, 2009), yaitu: (1) obyek/atraksi dan daya tarik wisata; (2) transportasi dan infrastruktur; (3) akomodasi; (4) usaha makanan dan minuman; dan (5) jasa pendukung lainnya untuk mendukung kelancaran berwisata, seperti: biro perjalanan yang mengatur perjalanan wisatawan, penjualan cindera mata, informasi, jasa pemandu wisata. Selanjutnya Cooper (2011) menyebutkan konsep komponen dari destinasi pariwisata terdiri atas: attraction, access, amenities, and ancillary services (4A). Komponen 4A ini dapat untuk digunakan sebagai rujukan dalam menjelaskan komponen destinasi pariwisata (DTW).

Berikut dijelaskan tentang kelayakan dari "Pasiraman Pura Dalem Pingit dan Pura Kusti" ditinjau dari konsep komponen 4A yang dimiliki, seperti:

\section{Attraction}

Air Suci ini berbentuk seperti air terjun dengan tinggi \pm 2 meter. Air suci ini dapat menunjukkan kondisi dari pengunjung yang melakukan penglukatan. Melukat merupakan prosesi yang dilakukan manusia guna membersihkan diri secara jasmani dan rohani. Dalam umat Hindu, melukat biasanya dipimpin oleh seorang pemangku dimana sebelumnya dilakukan persembahyangan kemudian dilanjutkan dengan penyiraman air suci. Namun boleh juga melukat yang dilakukan langsung tanpa dituntun pemangku di "Pasiraman Pura Dalem Pingit dan Pura Kusti” ini.

Pada saat melukat di DTW ini warna dari air dipercaya dapat berubah tergantung dari kondisi kesehatan secara fisik maupun non-fisik pengunjung. Selama ini warna air berbeda yang pernah disaksikan oleh pemangku pura hanya ada tiga, yaitu: (1) putih keruh seperti air cucian beras; (2) keruh kekuningan; dan (3) merah seperti air teh. Makna dari ketiga warna air berbeda selain bening seperti air biasa ini tidak dapat ditafsirkan secara pasti artinya karena hal ini merupakan sebuah kepercayaan yang sulit dibuktikan secara ilmiah. Pemangku sulit memberikan makna pasti pada tiap-tiap warna air tersebut mengingat hal tersebut tidak terbukti secara langsung. Menyaksikan khasiat air suci ini membuat wisatawan tertarik untuk melakukan penglukatan. Pengunjung yang datang ke tempat ini percaya bahwa melukat dapat memberi manfaat positif bagi pengunjung, seperti memunculkan rasa tenang dan nyaman. 
Adapun tata cara untuk melukat di pura ini, yaitu sebelum melakukan penglukatan pengunjung harus bersembahyang di sebuah pelinggih yang terletak di dekat air suci dengan tujuan meminta izin untuk melakukan penglukatan kemudian melanjutkan ke arah arah air suci dan bersembahyang sekali lagi dalam posisi berdiri dengan kwangen yang sudah digunakan pada persembahyangan sebelumnya dan menghanyutkannya pada saat melukat nanti. Pada kompleks air suci ini terdapat dua aliran air suci yang tidak terlalu tinggi, dimana air suci yang berada di sebelah kanan atau yang lebih dekat, dengan jalan menuju air suci ini yang digunakan untuk melukat pertama yang dipercaya dapat membersihkan diri dari penyakit. Jika warna air yang digunakan melukat memiliki warna yang tidak biasanya, disarankan untuk tetap berada di bawah air suci hingga warna air menjadi jernih kembali, karena jika air kembali jernih dipercaya sakit yang ada pada diri orang yang melukat telah hilang.

Setelah melakukan penglukatan, air dari air suci tersebut diminum sebelas kali, dan dilanjutkan melukat ke air suci kedua. Sebelum meninggalkan pura, harus dilakukan persembahyangan untuk terakhir kali di pelinggih yang berada di dekat pelinggih sebelumnya. Tujuannya untuk meminta izin meninggalkan areal pura dan meminta keselamatan selama perjalanan pulang. Walaupun prosesi ini konsepnya berasal dari ajaran Hindu, pengunjung yang memiliki keyakinan lain masih tetap dapat melukat, dimana pengunjung tersebut tidak diharuskan melakukan persembahyangan di pelinggih pura. Namun, disarankan tetap meminta izin untuk melukat menggunakan cara sesuai keyakinan mereka masing-masing.

Manfaat langsung yang didapat setelah melukat berupa ketenangan/kesehatan lahir batin. Selain itu, melukat juga merupakan sebuah daya tarik yang menjadi hal utama datangnya wisatawan ke pura ini, terutama bagi penderita penyakit yang tidak dapat disembuhkan secara medis. Khasiat yang dipercaya oleh masyarakat adalah dapat menyembuhkan berbagai penyakit yang diderita. Keberadaan alam yang asri ini sangat penting dalam mendukung kegiatan wisata spiritual karena dari alam yang asri ini memberikan udara yang segar dan suasana sejuk. Ke depan diharapkan tidak terjadi kerusakan ataupun pengalihan fungsi lahan di sekitar pura ini. Masyarakat desa Sebatu memiliki kepercayaan hutan bambu di area pura sebagai tempat tinggal dari "penjaga niskala (tak kasat mata)" dari "Pasiraman Pura Dalem Pingit dan Pura Kusti” sehingga tidak ada masyarakat yang berani menebang ataupun merusak hutan di sekitar pura.

\section{Access}

Akses merupakan salah satu unsur penting dari daya tarik wisata karena tanpa ada akses wisatawan tidak akan bisa menuju ke daya tarik wisata. Lokasi dari "Pasiraman Pura Dalem Pingit dan Pura Kusti” berada diantara beberapa daya tarik wisata terkenal, seperti Pura Tirta Empul, Ubud, dan Desa Taro. DTW ini berada di jalur yang strategis, dimana jalur tersebut sering digunakan untuk tour, menuju DTW di sekitar Kintamani Bangli. Strategisnya lokasi pura ini dapat dijadikan salah satu alternatif bagi wisatawan pecinta wisata spiritual.

Sebelah timur Desa Sebatu terdapat sebuah DTW spiritual yang sudah terkenal yaitu Pura Tirta Empul Tampaksiring. Keberadaan pura ini dapat menjadi pendukung perkembangan "Pasiraman Pura Dalem Pingit dan Pura Kusti”. Jarak dari kedua pura hanya 15-20 menit dengan kendaraan bermotor. Sebelah selatan Desa Sebatu cukup dekat dengan Ubud (Monkey Forest, Puri Ubud/Ubud Palace) hanya berjarak 
sekitar 1 jam. Sebelah barat Desa Sebatu berbatasan dengan Desa Taro yang sudah sangat terkenal dengan wisata menunggang gajahnya, dengan jarak 10-15 menit.

Terdapat dua jalan utama menuju pura ini jika berangkat dari Denpasar atau Badung. Jalur yang pertama adalah melalui Jalan Raya Batu Bulan menuju Ubud melalui Jalan Raya Lodtunduh dan tiba di Jalan Raya Pengosekan. Selanjutnya menuju Jalan Raya Pengosekan, Jalan Raya Tegallalang, dan terakhir melalui Jalan Raya Pujung. Jalur ini memiliki panorama yang indah dimana terdapat alam persawahan yang membentang luas yang menjadi daya tarik tersendiri selama perjalanan.

Jalur kedua, yaitu melalui jalur Tampaksiring. Tepatnya melalui Jalan Raya Batu Bulan menuju ke Jalan Raya Mas, melewati Jalan Raya Goa Gajah, kemudian Jalan Raya Pejeng dan Jalan Raya Tampaksiring. Jalur ini umumnya digunakan bagi wisatawan yang melakukan wisata religi atau spiritual, karena pada jalur ini wisatawan dapat melakukan kegiatan wisata spiritual di Pura Tirta Empul Tampaksiring kemudian lanjut ke "Pasiraman Pura Dalem Pingit dan Pura Kusti”. Kondisi alam pada jalur ini masih alami dengan udara sejuk. Selain alam yang masih alami, jalur ini juga melintasi pemukiman warga. Jadi wisatawan dapat melihat masyarakat dengan kegiatan sehari hari mereka seperti bertani dan memahat patung. Kondisi jalan untuk menuju tempat melukat masih cukup baik, karena jalan terbuat dari aspal dan aman bagi pejalan kaki yang akan melukat. Sepanjang jalan menuju tempat $m e$ lukat, terdapat banyak pedagang yang menjual berbagai sarana sembahyang, kerajinan tangan, hingga jajanan bagi pengunjung yang beristirahat setelah melukat.

\section{Amenities}

Fasilitas yang terdapat di "Pasiraman Pura Dalem Pingit dan Pura Kusti” yang mendukung kenyamanan wisatawan selama melakukan kegiatan "melukat" diantaranya tempat parkir, warung makan dan restoran, pedagang alat persembahyangan, ruang ganti dan penitipan barang serta toilet umum.

a. Tempat parkir

Tempat parkir di Pasiraman Pura Dalem Pingit dan Pura Kusti dapat menampung sekitar 50 sepeda motor dan 20 kendaraan roda empat. Pada saat ramai pengunjung, biasanya parkir juga dibolehkan di pinggir sepanjang jalan utama. Parkir kendaraan diatur oleh petugas parkir dari masyarakat lokal agar kendaraan tetap aman dan rapi. Hal serupa juga diterapkan dalam pengelolaan desa wisata Serangan, dimana petugas parkir untuk mengatur lalu lintas kendaraan direkrut dari masyarakat setempat (Oka, dkk (2018). Dalam penelitian Winia, dkk (2019) juga disebutkan bahwa pemberdayaaan masyarakat lokal telah dilakukan di desa wisata guna meningkatkan kesejahteraan masyarakat. Hal ini dilakukan mengingat mereka merupakan pemilik utama dari destinasi wisata yang dikembangkan sebagai destinasi wisata berkelanjutan.

b. Warung makan dan restoran

Masyarakat telah menyediakan warung makan/restoran bagi wisatawan atau pengunjung yang ingin makan atau hanya duduk setelah melakukan pembersihan diri (melukat). Di sepanjang jalan terdapat 6 unit warung yang menyediakan makanan/ minuman dan 2 unit berada di areal pura. Satu unit restoran terletak di sirkuit pengunjung tempat keluar dari pura yang memiliki pemandangan hutan dan sawah yang masih asri. Restoran ini juga dikelola oleh masyarakat Desa Sebatu. 
c. Pedagang alat persembahyangan

Bagi wisatawan dan pengunjung yang ingin melukat di "Pasiraman Pura Dalem Pingit dan Pura Kusti” yang tidak membawa alat persembahyangan, dapat membeli peralatan sembahyang di tempat ini. Ada pedagang yang menjual alat-alat persembahyangan. Peralatan sembahyang yang dijual di sini berupa kwangen, dupa, canang, jerigen kecil, kain, serta keben.

d. Ruang ganti dan penitipan barang

Ruang ganti ini masih berupa dua bilik dengan tembok setinggi bahu dan tidak terdapat pintu. Masyarakat lokal juga menyediakan tempat penitipan barang untuk mencegah hilangnya barang-barang berharga milik wisatawan dan pengunjung selama melukat. Tempat penitipan barang ini berupa laci-laci kecil dan kunci dari laci-laci tersebut akan diberikan kepada wisatawan/pengunjung

e. Toilet (WC umum)

Terdapat empat unit toilet umum di sekitar 'Pasiraman Pura Dalem Pingit dan Pura Kusti'. Dua unit toilet berada di dekat tempat parkir dan kondisinya masih sangat baik dan dua unit lagi berada sirkuit pengunjung dekat air suci.

\section{Ancillary Service}

Pengembangan pura secara swadaya dilakukan masyarakat lokal Desa Sebatu membuat pihak pengelola perlu untuk melengkapi dengan fasilitas seperti tourist information centre dan sign berbahasa asing untuk memudahkan pengunjung. Namun demikian sudah ada fasilitas puskesmas di desa sebagai tempat untuk berobat bagi pengunjung yang mengalami kecelakaan selama perjalanan menuju pura.

Awalnya pura ini dibangun hanya untuk kapasitas desa, dan masyarakat tidak berpikir akan dapat menarik banyak pengunjung. Antusias masayarakat Bali sangat besar untuk melakukan kegiatan wisata spiritual membuat pura ini selalu ramai pada saat hari raya umat Hindu, hari minggu ataupun hari libur. Hal ini dapat menyulitkan wisatawan yang ingin melihat-lihat sekaligus melukat. Sering terjadi antrian pada sirkuit pengunjung menuju air suci mengingat luas pura hanya sekitar 8 are, sudah termasuk asilitas tempat ganti, air suci dan sungai yang mengalirkan air dari air suci.

Merujuk penjelasan di atas dapat dikatakan bahwa Pasiraman Pura Dalem Pingit dan Pura Kusti telah memenuhi syarat untuk dikembangkan menjadi daya tarik wisata (DTW). Komponen kualifikasi DTW yang dimiliki, yaitu: (1) attraction, terdiri atas: Pesiraman Pura Dalem Pingit dan Pura Kusti, (2) access, yaitu terdapat 4 akses inftastruktur berupa jalan menuju ke pura; (3) amenities, yaitu memiliki fasilitas pendukung seperti: sarana parkir, warung makan, pedangang alat persembahyangan, ruang ganti pakaian, toilet; dan (4) ancillary service, yaitu terdapat fasilitas desa yang dapat menunjang kegiatan pariwisata, seperti puskesmas. Hal tersebut sangat dibutuhkan dalam menunjang kelancaran wisatawan untuk mencapai dan menikmati keindahan dari daya tarik wisata.

\section{PENUTUP}

Pasiraman Pura Dalem Pingit dan Pura Kusti telah memenuhi kualifikasi (layak) untuk dikembangkan menjadi daya tarik wisata (DTW) karena telah memenuhi kualifikasi yang dipersyaratkan. Komponen kualifikasi DTW yang dimiliki, yaitu: (1) attraction, yaitu: Pasiraman Pura Dalem Pingit dan Pura Kusti; (2) access, yaitu infrastruktur yang memadai untuk menuju ke pura; (3) amenities, yaitu memiliki fasilitas pendukung memadai, seperti: sarana parkir, warung makan, pedangang alat 
persembahyangan, ruang ganti pakaian, dan WC umum, dan (4) ancillary service, memiliki fasilitas pendukung puskesmas. Disarankan kepada pihak pengelola harus mengelola DTW Pasiraman Pura Dalem Pingit dan Pura Kusti ini secara serius sehingga benar-benar dapat berkelanjutan. Di samping itu peran pemerintah daerah sangat dibutuhkan dalam mendukung pengembangan DTW baik dari segi dana maupun pelatihan manajemen.

\section{DAFTAR PUSTAKA}

Beerli, A. \& Martin, J. (2004). Factors Influencing Destination Image, Annals of Tourism Research, Vol. 31 (3), 657-681

Budiasih, M. (2017), Pariwisata Spiritual di Bali, Jurnal Ilmiah Agama dan Budaya, Vol. 2 (1). P. 70-80

Bungin, B. (2011). Metode Penelitian Kualitatif. Aktualisasi Metodologis ke Arah Ragam Varian Kontemporer. PT. Raja Grafindo Persada. Jakarta

Cole, S. (2012). A Political Ecology of Water Equity and Tourism: A Case Study from Bali. Annals of Tourism Research. 39 (2), 1221-1241.

Cooper, C. (2011). Essentials of Tourism. Oxford: Prentice Hall

Darmayanti, P. W., \& Oka, I. M. D. (2020). Implikasi Pengembangan Pariwisata Berbasis Masyarakat bagi Masyarakat di Desa Bongan. Jurnal Ilmiah Hospitality Management, $10 \quad$ (2), 142-150. doi: 10.22334/jihm.v10i2.167

Disparda (Dinas Pariwisata Daerah) Bali. (2019). Data Kunjungan Wisatawan Mancanegara ke Bali Denpasar

Oka, IMD, P. W. Darmayanti, \& I W.
Sonder. (2021). Turtle Conservation in Serangan Island: The Implementation of Community-based Tourism Concepts in Tourism Development. PalArch's Journal of Archaeology of Egypt / Egyptology, 18(2), 172-182. Retrieved from https://www.archives.palarch.nl/index.php/jae/article/view/5668

Oka, I. M. D., Winia, I. N., \& Sadia, I. K. (2019). The Implication of the Development of Serangan Tourist Village from the Economic Perspective. In International Conference on Social Science 2019 (ICSS 2019). Atlantis Press.

Oka, I. M. D., Winia, I. N., \& Sadia, I. K. (2018). Pemetaan Potensi Pariwisata Dalam Mendukung Pengembangan Pariwisata di Desa Serangan. Bhakti Persada Jurnal Aplikasi IPTEKS, 4(1), 47-54.

Oka, I. M. D., Winia, I. N., \& Sadia, I. K. (2018, October). The Motivation of Serangan Community to Support the Development of Tourism at Serangan Village. In 1st International Conference on Social Sciences (ICSS 2018). Atlantis Press.

Oka, I. M. D., \& Pugra, I. W. (2017). The Impacts of Balinese Women Working in Cruise Ship. International Journal of Applied Sciences in Tourism and Events, 1(1), 51.

Lagatama, P. \& Putra, N. D. (2020). Aktivitas Yoga sebagai Produk Pemasaran Jasa Wisata Spiritual, Jurnal Ilmiah Agama dan Budaya, Vol. 5 (1). hal. 30-34

Mahadewi, N.P.E \& I P. Sudana. (2017), Model StrategiPengembangan Desa Wisata Berbasis Masyarakat di Desa Kenderan, Gianyar, Bali. Jurnal Analisis Pariwisata. Vol. 17 (1), p 41-45

Mahardika, N., (2018). Esensi Melukat sebagai Daya Tarik Wisata Spiritual. Jurnal Pariwisata Budaya. Vol 3 (2), hal. 51-61. 
Putra, I N. D. dan I G. Pitana. (2010). Pariwisata Pro-Rakyat Meretas Jalan Mengentaskan Kemiskinan di Indonesia. Jakarta; Kementerian Kebudayaan dan Pariwisata.

Sadia, I. K., \& Oka, I. M. D. (2012). Motivasi Tenaga Kerja Bali Bekerja di Mediterranean Shipping Company (MSC). Jurnal Sosial Humaniora, Vol. 2 (3), 221-236.

Sastrayuda, G. (2010). Konsep Pengembangan Kawasan Ekowisata. Yogyakarta. Sindhu, P. (2014) Panduan Lengkap Yoga. Bandung: Qanita.

Sutrisna, E. (2011). Problematika Perempuan Bekerja di Sektor Pariwisata (Studi Kasus Perhotelan). Jurnal Aplikasi Bisnis.1 (2), 97-102
Utama, P. S. J. \& Wiguna, I M. A. (2020), Peluang dan Tantangan Pengembangan Wisata Yoga sebagai Produk Pariwisata Spiritual, Pariwisata Budaya: Jurnal Ilmiah Pariwisata Agama dan Budaya, hal. 42-48. $\quad$ http://ejournal.ihdn.ac.id/index.php/PB/index Doi: 10.36275/mwsh.

Winia, I. N., Oka, I. M. D., \& Pugra, I. W. (2019, October). The Implementation of the Community-based Tourism at Tista Tourist Village. In International Conference On Applied Science and Technology 2019-Social Sciences Track (iCASTSS 2019). Atlantis Press.

Zahra, I. (2012). Destination image and tourism: A case study of Bangladesh. European Journal of Business and Management. $4(6), 18-27$ 